\title{
Asia-Pacific Stock Returns around the Lehman Shock and Beyond: time-varying conditional correlations
}

Jun Nagayasu

University of Tsukuba, Tsukuba, Japan

\begin{abstract}
This paper attempts to identify economic and financial factors contributing to the changing correlations of recent stock returns. Time-varying correlations have been documented in previous studies, but few attempts have been made to investigate their evolution. Focusing on the Asia-Pacific region, this paper shows that daily return correlations tend to be higher in advanced countries, are negatively correlated with the distance between markets, and increase at times of active trading and financial turmoil. Furthermore, while some explanatory variables tend to lose their statistical significance during financial crises, volume data have strengthened their relationship with return correlations, particularly around the Lehman Shock.
\end{abstract}

JEL classification codes: F36, G15

Key words: Dynamic Conditional Correlations, Stock Returns, Lehman Shock, Greek Crisis, Distance

\footnotetext{
* Corresponding Author: Jun Nagayasu; Faculty of Engineering, Information and Systems, University of Tsukuba, 1-1-1 Tennodai, Tsukuba, Ibaraki 305-8573, Japan; Tel: +81 298535067, Fax: +81 298535067, Email: nagayasu@sk.tsukuba.ac.jp.

Acknowledgements: I would like to thank for comments an editor, anonymous referees, and participants at the annual meeting of the Nippon Finance Association (Tokyo). This paper was completed when the author was visiting University of Strathclyde (UK).
} 


\section{Introduction}

The analysis of stock correlations is closely linked with putting together a financial portfolio. For example, standard economic theories, such as the capital asset pricing model, recommend the collection of negatively correlated stocks as a guide for diversification. Since financial assets form an important part of wealth and thus are deeply connected with welfare (e.g., Lettau and Ludvigson 2001), people are keen on learning their correlations. For decades, this seems to have been a driving force for investors and researchers continuing to analyze stock correlations.

Today, financial diversification has an international dimension. Due to financial market deregulation and developments in IT, it has become common practice even for individuals to possess not only domestic but also foreign financial assets. While investment tends to have a home bias, a tendency for consumers to hold more domestic assets than foreign ones, this is a natural extension to a domestic diversification strategy since stocks in different countries are prone to face different types of shocks and thus the correlation between domestic and foreign assets is likely to be lower than one between domestic stocks. In this respect, holding only domestic assets may be thought of as a more risky strategy than one with both domestic and foreign assets.

It is also important for policymakers to understand stock correlations, in particular when the economy is slowing down. Obviously, when home stocks are positively correlated with foreign stocks, poor performance overseas will adversely influence domestic stocks. This adverse effect from one country to another during crises is often called contagion as opposed to spillover, which may occur even during tranquil periods. The extent to which home stock prices decline in response to external shocks is reflected in the correlation between domestic and foreign financial assets. The higher their correlation, the greater the negative impact on the domestic assets. In this way, stock return correlation has been used to measure the level of capital market integration among other criteria (e.g., Baele et al. 2004).

Against this background, this paper will focus on correlation of volatility that represents uncertainty in financial markets. The analysis of volatility correlation is increasingly important in recent periods, when series of financial crises have erupted and return volatility has increased. Indeed, it is even difficult to find a tranquil period since the Lehman Shock, and crises are no longer events that occur once in a hundred years but almost every single year (Nagayasu 2013). Note that we do not mean to focus on contagion effects, but to analyze the overall correlation of stock returns as our study covers tranquil periods as well. For this reason, we shall calculate a time-varying correlation using the Dynamic Conditional Correlation (DCC) method (Engle 2001) and shall attempt to explain the evolution of the correlation of stock returns in the Asia-Pacific region.

While some similar research has been carried out (Pretorius 2002, Yang 2005, Chintrakarn 
and Prasatkitjaroen 2010), this study is different in a number of respects. First, our dataset is unique in including developing countries, such as India and mainland China, while also containing the period of the 2008 Lehman Shock and the early period of the European sovereign debt crisis triggered in Greece in 2009. This is in contrast to previous research that focused largely on stock return correlations around Black Monday and the 1997 Asian crisis.

Second, unlike most existing literature, we shall investigate the relationship between correlations and their explanatory variables using high frequency (daily) data and the recursive method, which enables us to obtain robust results linked to the timing of financial crises that are unknown to us. Use of daily data is rare in this type of research since there is a tradeoff between the number of observations and explanatory variables. However, since we have opted to cover a wide range of countries, including those that do not have a long history of data dissemination, it is necessary for us to use higher frequency data in order to maximize the number of timeseries observations and obtain statistically reliable results.

Finally, this study is motivated by developments in Multivariate-Generalized Autoregressive conditional heteroscedasticity (M-GARCH) models. Since financial assets are volatile and highly correlated, it is more appropriate to model them in the context of the M-GARCH. In the past, technical difficulties often prevented researchers from estimating time-varying correlations, and investors often compromised by using a constant correlation for their analysis.

\section{Literature Survey}

Since stock return correlation is an important issue for consideration when making financial investment decisions and is also used to measure financial market integration, it draws considerable interest from researchers. These studies can be conveniently divided into two areas: one investigating the stability of stock return correlations, and the other trying to explain the driving forces of time-varying correlations. There is a lot of research on the former, but little exists on the latter. In addition, we review recent papers from the perspective of developments in estimation methods.

As regards the stability of stock return correlations, the presence of financial market interdependence has often been confirmed using stock prices or return data. Classic studies include Levy and Sarnat (1970), who showed a positive correlation ranging from 0.09 to 0.81 in data from advanced countries from 1951 to 1967. Hamao et al. (1990) confirmed this result and furthermore reported a unidirectional causality from New York (NY) to London and London to Tokyo. While evidence of unidirectional causality appears to have become weaker as a result of the development of financial markets across the world (Lin et al. 1994), correlations between markets are shown to exist even when more recent data are analyzed and country coverage is expanded to include emerging markets (Masih and Masih 1997). 
Furthermore, return correlations are apparently time-varying and tend to increase at times of financial crises. Unstable correlations over time are documented in Makridakis and Wheelwright (1974) and Longin and Solnik (1995), and an increase in correlations during crises was found, for example, by King and Wadhwani (1990), who investigated the October 1987 crash (or Black Monday). They reported that correlations between the London and NY stock markets increased from 0.27 to 0.65 during the crisis but dropped to 0.19 after the crash effects ceased and the market returned to normal. Similar evidence was obtained for emerging markets too. A surge in return correlations was reported after Black Monday (Liu et al. 1998), the 1994 Mexican peso crisis (Calvo and Reinhart 1996), the Asian crisis (Yang 2005), and a series of recent financial crises (Bayoumi et al. 2007).

Given that there is evidence of time-varying correlations, some studies - although not many - have carried out investigations of their explanatory variables. For example, Roll (1992) pointed to time zone differences as one reason for heterogeneous return correlations. He shows that European markets have a low correlation (less than 0.3) with the US, but have a high correlation with other European countries ( 0.7 between Germany and Switzerland). Similarly, Flavin et al. (2002) and Baker and Loughran (2007) confirm the importance of differences in location in explaining return correlations. To the extent that neighboring countries tend to share similar endowments, Roll also notes that a similar industrial structure between countries leads to a high degree of correlation in stock returns. While these studies discuss geographical location to explain differing correlation levels between countries, location can also be used to explain the time-varying correlations since geographical proximity implies both similar opening hours of the stock exchanges and simultaneous inflows of new information to those countries.

In addition, some researchers have argued that the country's openness was a critical factor in explaining the development of correlations. In this connection, Chen and Zhang (1997) used monthly data from 1980 to 1990 and empirically emphasized the important role of international trade through which the financial markets are linked. Pretorius (2002) conducted a comprehensive study using a wide range of quarterly data from 1995 to 2000, such as international trade level, inflation differentials, interest rate differentials, economic growth, and volatility of returns. From a panel data regression for 10 emerging markets, the intensity of trades was found to be positively associated with correlations.

Finally, one direction in recent studies is closely related to developments in estimation techniques. In particular, a lot of recent research on correlation and thus capital market integration has been conducted in the DCC-GARCH(Dynamic Conditional ComelationGeneralized Autoregressive Conditional Heteroskedasticity) context. For example, Lahrech and Sylwester (2011) used the DCC to investigate co-movements in stock returns between the US and Latin American countries (Argentina, Brazil, Chile, and Mexico) and showed evidence of an increased integration over the years. Furthermore, Chiang et al. (2007) and Kuper and Lestano (2007) investigated financial contagion using the DCC for Asian countries around the Asian crisis, and the former concluded that credit ratings have influenced the correlation 
structure during the Asian crisis.

The DCC is also used to measure correlation between stock returns and other financial asset returns. In an analysis of the recent European financial crisis, Tamakoshi et al. (2012) showed that the correlation between government bond yields and stock returns has declined during this crisis. The DCC is also employed to investigate the relationship between commodity prices and stocks (Choi and Hammoudeh, 2010). Their evidence suggests an increased correlation among commodity prices since the 2003 Iraq war, but a decline in their correlation with US stocks (S\&P).

\section{Methodology and Data}

Since there is clear evidence of interdependence in stock returns and of the Lehman Shock having adversely affected stock performance in global markets (Al-Rjoub and Azzam, 2012), we shall estimate time-varying correlations using the DCC model (Engle 2002). This model is a breakthrough for practitioners and researchers alike since conditional correlations were often assumed to be constant in M-GARCH models due to computational (rather than theoretical) reasons. ${ }^{1}$ While there are several statistical methods for obtaining time dependent correlations, Engle (2002) discussed the deficiencies of such methods previously employed by a number of researchers. $^{2}$

We employ the most orthodox specification and estimation method for the DCC-GARCH here, and for the vector of stock returns $\left(r_{t}\right)$, the model specification can be expressed as:

$$
\begin{gathered}
r_{t} \mid F_{t-1} \sim N\left(0, H_{t}\right) \\
H_{t}=D_{t} R_{t} D_{t}
\end{gathered}
$$

where $H_{t}$ is a covariance matrix and $t$ presents time $(t=1, \ldots, T)$. Furthermore, $R_{t}$ is a timevarying correlation matrix and is of interest to us, and $D_{t}$ is $\operatorname{diag}\left(\operatorname{sqr}\left(h_{i t}\right)\right)$ and is a matrix of timevarying standard deviations for country $i(i=1, \ldots, N)$. Since this model becomes the Constant Conditional Correlation (CCC) model when $R_{t}=R$, the DCC can be viewed as an extension of the CCC.

The unique feature of this model is its ability to treat conditional variances $(D)$ and the correlation matrix $(R)$ separately, which makes the concept of time-dependent correlations

\footnotetext{
${ }^{1}$ The traditional M-GARCH often faces the problem of obtaining convergence during estimation when the number of variables increases. The classic study Bollerslev et al. (1998) considered only three asset returns in their M-GARCH.

${ }^{2}$ For example, both rolling correlation and RiskMetrics approaches are based on a particular value of weights being attached to past observations, but there is no theoretical guidance to justify these weights in these models.
} 
operational. With respect to the former, Engle proposed obtaining time-varying standard deviations, $\operatorname{diag}\left(\operatorname{sqr}\left(h_{i t}\right)\right)$, from a univariate $\mathrm{GARCH}$ model such as $\operatorname{GARCH}(1,1)$.

$$
h_{i t}=\omega_{i}+\alpha_{i} r_{i t-1}^{2}+\beta_{i} h_{i t-1}
$$

The conditions $\alpha_{i}, \beta_{i} \geq 0$ and $\alpha_{i}+\beta_{i}<1$ ensure non-negativity of variances and the meanreverting process of the data. Obviously, other types of GARCH models, like the Integrated GARCH, can be used to specify conditional covariance, but this paper utilizes the most standard model GARCH $(1,1)$ since it captures reasonably well the data generating process of our data.

As regards the correlation matrix, the dynamic correlation is proposed to have the next structure.

$$
R_{t}=\operatorname{diag}\left(Q_{t}\right)^{-1} Q_{t} \operatorname{diag}\left(Q_{t}\right)^{-1}
$$

where $Q_{t}$ is a symmetric positive definite matrix and is assumed to be $Q_{t}=(1-a-b) \bar{Q}+$ $a\left(\varepsilon_{t-1} \varepsilon_{t-1}^{\prime}\right)+b Q_{t-1}$. The $\bar{Q}$ is the unconditional variance of the standardized residual $\left(\varepsilon_{t}=D_{t}^{-1} r_{t}\right.$ and $\left.\varepsilon_{t} \sim N\left(0, R_{t}\right)\right)$, and the parameters, $a$ and $b$, are non-negative with $a+b<1$ for the model to be mean-reverting. In short, there will be $N(N-1) / 2$ combinations of conditional correlations. For the estimation, we follow the two-step method proposed by Engle (2002).

This method will be applied to our data, which cover the sample period from 2005/10/10 to 2011/07/14 (daily data) for 9 Asia-Pacific countries: namely; Australia, China, Hong Kong (HK), India, Indonesia, Japan, New Zealand (NZ), South Korea, and Taiwan (see Appendix). The beginning of the sample period and the country coverage are determined by the availability of data, including those used to explain the evolution of the correlations (See Section V) ${ }^{3}$. Daily frequency is chosen in order to maximize the number of observations. The major stock index in each country, which is based on a local currency, is chosen for our analysis and is listed in Table 1.

Stock prices normalized at the time of the Lehman bankruptcy $(2008 / 09 / 15=100)$ are shown in Figure 1. For illustrative purposes, we define two historical events: Crisis I (2008/01/01 2009/06/12) and Crisis II (2009/12/08 2010/05/02). Our definition of Crisis I is closely related with the sub-prime loan problem in the US, and does not start from the date of the Lehman Shock (2008/09/15). The sample period begins when stock prices in most countries started to decline radically along with increases in uncertainty about the prospects of financial institutions worldwide (see Figure 1). The end-period is determined by the time of the Nikkei225 regaining the level of 10,000 yen for the first time since the crisis (2009/06/12).

\footnotetext{
${ }^{3}$ For example, the volume data for the Shanghai Composite are available only from $2005 / 10 / 10$, and there is no volume data for our sample period for other important stock indices such as the KLSE Composite and the STRAITS Times indices.
} 
The Nikkei was used to decide the end-date since Japanese stock price recovery was slowest among the countries under investigation. More generally, stock price recovery tends to be slow in advanced countries.

Crisis II is closely associated with the Greek sovereign debt crisis. The beginning of this crisis period in the figure is determined by the time of Fitch downgrading Greece's rating from $\mathrm{A}-$ to $\mathrm{BBB}+$, and the end by the date when euro member countries and the IMF agreed to give Greece a $€ 110$ billion loan. Judging from the graph, the impact of Crisis I on stock returns is far bigger than that of Crisis II.

Note that we use this information on the timing of financial crises for preliminary analysis. In the subsequent study where time-varying correlations are formally analyzed, we employ the time-variant parameter model where changes in parameters are endogenously determined without a priori information about crisis periods.

\section{Summary Statistics}

Table 2 summarizes the basic statistics of stock returns and shows that stock markets in developing countries performed better than those in advanced countries. While the average of stock returns is negative for Japan, implying a declining trend in their prices, Chinese, Indian, and Indonesian stock markets performed strongly during our sample period. Such a clear contrast between advanced and non-advanced countries cannot be seen in terms of the stock volatility measured by the standard error. We also confirm the significant presence of ARCH effects in all series using Engle's test and a violation of the constancy of the correlations in the multivariate AR(1)-GARCH(1, 1) context using the Lagrange Multiplier (LM) test (Tse 2000) and the Engle-Sheppard test (2001). The Autoregressive term AR(1) is added to the estimation model in order to capture the persistence of stock prices (returns), which is generally accepted among researchers (Greene and Fielitz 1977). Thus, our results support employing the ARDCC-GARCH-type model.

The parameters of conditional variance equations from the $\operatorname{AR}(1)-\operatorname{DCC}-\operatorname{GARCH}(1,1)$ are estimated by the 2-step maximum likelihood estimation approach (Engle 2002) where the first step involves estimation of ARCH/GARCH components for each pair, and the second step includes estimation of conditional correlations using parameters obtained in the first step. As expected, ARCH and GARCH parameters are positive and their sum is below unity from the first step of the model estimation (Table 3). The $Q$ test is also conducted to check if there is autocorrelation in each equation, and shows that generally our specification is appropriate,

\footnotetext{
${ }^{4}$ Following the country classification of the IMF, advanced countries include Australia, HK, Japan, Korea, NZ, and Taiwan; and the developing countries are China, India, and Indonesia (as of this writing).
} 
although there are two instances out of 18 where the model suffers from this problem at the five percent significance level. $^{5}$

The second step of the DCC estimation (Table 3) shows that the estimates are statistically significant and within the theoretical range suggesting a covariance - stationarity process. This result is consistent with the Tse and Engle-Sheppard constancy test results, and thus confirms the importance of time-varying conditional correlations.

Estimates of time-varying correlations are summarized in Table 4 and Figure 2. Table 4 lists country pairs ( $i$ and $j$ ) according to the average size of conditional correlations. Interestingly, there is a tendency for pairs of advanced countries to have higher conditional correlations. For example, a high correlation exists between Japan-Korea and Australia-Japan, and a low correlation between China-New Zealand. Furthermore, the correlation between China and Hong Kong is relatively high (ranked around the middle in Table 4), but that between China and Taiwan is low, although these three countries can be grouped as a Chinese speaking region. If one considers correlation to be a measure of capital market integration, our result implies high integration between advanced countries and low integration between any pairing involving one or more developing countries. This table also shows that the conditional correlation is high in moments of chaos, particularly during Crisis I (see average in Table 4). Finally, Figure 2 shows that estimates of conditional correlations are generally changing by a magnitude of $0.1 \sim 0.2$.

\section{Empirical Findings}

\section{A. Model specification}

What changes the level of conditional correlations? Our choice of explanatory variables reflects information from existing literature and our daily data frequency. The latter limits the scope for using many explanatory variables, although it provides more observations for a given sample period. Furthermore, in order to deal with the multicollinearity problem, this study does not consider a wide variety of low frequency variables, like international trade and economic structure, but includes the distance between markets, volume of stocks, market size, the interest rate differential, and the dummy. Since we have already discussed most variables when reviewing previous literature, here we focus mainly on their theoretical relationship with return correlations.

The first explanatory variable is the physical distance, Dist between financial markets. The motivation for the inclusion of this variable is to measure the proximity of economic structure;

\footnotetext{
${ }^{5}$ There was no improvement when different lag orders were used in the specification.
} 
when countries possess a similar structure, they are likely to respond to external shocks in a similar way. It follows that distant countries are more heterogeneous, and thus it is expected for Dist to be negatively associated with stock return correlations. Table 5 shows that the longest distance is obtained between India and New Zealand, and the shortest between Taiwan and China (Shanghai). In addition, Hong Kong and Taiwan are located within a similarly short distance.

Another variable, the volume of traded stocks, $\mathrm{Vol}$ should be positively associated with correlations. In other words, active trading is expected to increase the return correlations through rapid price adjustments. Trading volume is higher during chaotic periods; the daily average of trading volume for all pairs of countries is $1.84 \mathrm{E}+09$ during the tranquil period, and $1.91 \mathrm{E}+09$ and 2.43E+09 during Crisis I and Crisis II, respectively. For analysis, we consider individually the impact of the volume of each country $(i$ and $j, i \neq j)$ on the correlations. The volume data are named as $\mathrm{Vol}_{i}$ and $\mathrm{Vol}_{j}$, where $i$ and $j$ are defined in Table 4.

The market capitalization differential, CapDiff is considered here in order to capture the similarity of financial markets in terms of their size. Market capitalization is used as a proxy for transaction costs and market liquidity (Pretorius 2002). The high value of market capitalization suggests a high level of development in financial markets with low transaction costs and high market liquidity. Since the absolute value of a difference in the market capitalization (in US dollars) between countries is used, the large size of this variable indicates dissimilarity in the markets. Thus, we expect a negative relationship between $\mid$ CapDiff $\mid$ and time-varying correlations.

Interest rate differentials, IntDiff are used to measure discrepancies in the stance of monetary policies between countries. Since the central banks often guide the market through controlling interest rates, a large difference in the absolute value of this variable indicates that countries have implemented different types of monetary policy in order to deal with heterogeneous economic and financial conditions. Thus, a negative relationship between $\mid$ IntDiff $\mid$ and correlation is expected to exist.

Finally, we use a dummy variable to capture potential unique features shared by countries. In particular, a dummy, ChinaDummy is introduced to capture the effects of the Chinese region (China, HK, and Taiwan) where the cultures are very similar. Thus, an extra positive effect is expected to show a higher correlation among these regions.

Using these data, the following equation is statistically estimated, on the basis of the random effects model, using the maximum likelihood estimation method. ${ }^{6}$

\footnotetext{
${ }^{6}$ The standard statistical estimation is not normally applicable to an endogenous variable, which ranges from one to zero. However, our panel Tobit analysis, which is not presented here due to brevity, suggests that that estimated values rarely exceed this theoretical boundary. Indeed, a similar specification, treating time-varying correlations as the endogenous variable, has been carried out in the past (e.g., Chintrakarn \& Prasatkitjaroen, 2010, and Fidrmuc et al., 2012). Furthermore, the fixed effects model is considered as one way to estimate it, but we often face the multicollinearity problem since the constants, Dist and ChinaDummy, are also considered in our specification. Thus, only results from the random effects model are reported here.
} 


$$
\begin{aligned}
{\text { DCC_ } r_{i j, t}} & \beta_{0}+\beta_{1} \text { Vol }_{i, t-1}+\beta_{2} \text { Vol }_{j, t-1}+\beta_{3} \mid \text { CapDiff }_{i j, t-1} \mid+\beta_{4} \text { Dist }_{i j} \\
& +\beta_{5} \mid \text { IntDiff }_{i j, t-1} \mid+\beta_{6} \text { ChinaDummy }_{i}+\varepsilon_{i j, t}
\end{aligned}
$$

where $D C C \_r$ is a conditional correlation of stock returns from the AR(1)-DCC-GARCH(1, 1 ), and $X_{i j, t}$ indicates variable $X$ for a pair of countries $i$ and $j$ at time $t$. Greek letters are parameters of interest to be estimated, and $\varepsilon$ is the residual $\left(\varepsilon_{i j, t}=u_{i j}+e_{i j, t}\right.$ where $u_{i j}$ is the unobservable individual specific effect, which is assumed to be random). For some variables, their lagged values are used in order to deal with a potential endogeneity problem. ${ }^{7}$ Thus our model is analogous to the gravity model that is often used to study the pattern of international trade. ${ }^{8}$

\section{B. Estimation results}

The results are summarized in Table 6 that shows two results from different model specifications, i.e., with or without ChinaDummy.

Generally, many explanatory variables are found to be useful in explaining return correlations (Table 6 [A]). For example, as regards the volume, our result suggests an increase in correlations at times of active trading, and this positive relationship is strong and statistically significant at the $1 \%$ level. Given the increased trading volume during financial crisis periods, this result suggests high return correlations, consistent with Table 4. Furthermore, this conclusion is valid for two types of volumes, i.e., $\mathrm{Vol}_{i}$ and $\mathrm{Vol}_{j}$.

Similarly, there are several variables which show significant explanatory power over the time-varying correlations. For example, $\mid$ CapDiff $\mid$ is reported to be statistically significant, and its negative parameter suggests an increase in the correlations when the markets are similar in terms of the market capitalization. This variable also implies similar developments and conditions in financial markets as the market capitalization measures the levels of market liquidity (Pretorius 2002). Similarly, interest differentials, $\mid$ IntDiff $\mid$ are also found to have the correct sign with statistical significance. An increase in this variable, which reflects the different stance in monetary policies between countries experiencing different business cycles, results in a fall in the level of correlation. This is consistent with the fact that developing countries (like China and India) often exhibited a strong economic performance during most sample periods, but developed countries (like Japan) have been suffering from recession. Thus, these findings support the view that higher correlation exists between countries/markets which have experienced a similar economic trend.

\footnotetext{
${ }^{7}$ We also examine the contemporaneous relationship (i.e, without taking the lag for explanatory variables) of equation 5 . But the conclusion drawn from such an analysis does not alter that presented in this paper.

${ }^{8}$ We did not implement the spatial econometric technique since it is difficult to define the geographic distance between a pair of correlations, which in our analysis involves four countries.
} 
Furthermore, consistent with our expectation, the distance between markets, Dist is negatively and significantly associated with return correlations. This finding is consistent with Roll (1992), Flavin et al. (2002), and Baker and Loughran (2007), although unlike previous studies, our dataset covers only Asia-Pacific countries and geographical distances are rather limited. Given that there have been developments in financial markets that facilitated reduction in transaction costs, the distance between markets can also be interpreted as the overlapping opening hours of the financial markets (Chintrakarn and Prasatkitjaroen 2010). If the markets are open at the same time, the arrival of new information occurs simultaneously, and thus increases correlations in these markets, particularly during crises. The importance of private information flows has been underlined by the microstructure model (O'Hara et al. 1997).

The only variable which turns out to be statistically insignificant is our dummy variable. A dummy to capture commonality among Chinese culture, ChinaDummy does not seem to affect the correlations. Thus, in order to check the robustness of previous findings to our model specification, we re-estimate the correlation equation without this dummy variable. Table 6 [B] confirms that our results in Table 6 [A] are generally robust. All explanatory variables maintain the same sign and statistical significance as before. The only exception is Dist, which is no longer significant, although it is correctly signed.

\section{Time-varying parameters}

Given our sample periods containing financial turmoil, the sensitivity of our findings to sample periods is analyzed by the recursive estimation of equation (5) without ChinaDummy, which was reported to be insignificant in our previous study. Since this method yields timevarying parameters, we do not require information on crisis periods prior to investigation. The first 100 observations are reserved for the initial estimation. It follows that time-varying parameters are obtained from 2006/02/27 to the end, and the figure shows a great fluctuation in many parameters.

Figure 3 shows estimates of changing parameters from the recursive regression method with a $95 \%$ confidence interval. Interestingly, some variables suggest a decline in the size of the parameter. Market capitalization, $\mid$ CapDiff $\mid$ exhibits a strong negative association with the return correlations in the early samples, but it has more or less ceased in our more recent observations. A similar trend can also be seen for interest rate differentials $\mid$ IntDiff $\mid$. Thus, our model suggests increased difficulty in explaining the correlations using economic fundamentals. This result can be interpreted as evidence that other factors such as investors' expectations may be increasingly important at times of financial crises. One possible explanation comes from the peso problem, a well-known phenomenon in international finance (Kaminsky, 1993), which suggests that even rational investors can keep making systematic mistakes if a true model for exchange rate determination alters over time. At chaotic moments, it is very likely that the true 
model is indeed changing dramatically.

In contrast, other variables have a more steady relationship with the return correlations. For example, parameters for the volume (both $\mathrm{Vol}_{i}$ and $\mathrm{Vol}_{j}$ ) are initially negative but turn to positive in 2007, and reach their peak around the time of the Lehman Shock. This is in line with the conventional belief that increased trading will raise the correlation level. Interestingly, the sensitivity of both volumes has slightly declined after September 2008 but remains positive during more recent periods. Thus, the volume seems to have functioned in harmonizing international stock markets more significantly during the Lehman Shock than at the time of the Greek crisis. The other variable, Dist, maintains the same sign over the period, so does the constant term. The positivity of the constant implies a close relationship between financial markets.

In short, the significance of economic and financial variables in explaining the evolution of return correlations is often variable - and time - specific. But there are some indicators which provide useful information about the level of return correlations.

\section{Conclusion}

Using the AR-DCC-GARCH and high frequency data, we examine time-varying return correlations in the Asia-Pacific markets for recent periods. Generally, this paper provides evidence that correlations tend to be higher in advanced countries and increase at times of active trading. Our finding of a higher correlation among advanced countries confirms a higher level of capital market integration between these countries. Furthermore, the stock correlation is rarely reported to be negative even when stocks in developing countries are considered. Thus, as a world phenomenon, at times of good performance of the world stock market, any country is likely to benefit from other countries; however, it will reverse when the world market is weak.

Furthermore, while the significance of some explanatory variables is found to be sensitive to the sample period, we report that return correlations are closely associated with some economic and financial factors. Of course, further research is needed, particularly for the ongoing Greek crisis, but as of this writing our explanatory variables, like volume, have been found to be significantly associated with return correlations, reflecting extensive trading in the crises. This is potentially a reflection of the herding behaviour of investors, which is widely perceived to exist prominently during crises due to information asymmetry. Furthermore, geographical distance between the markets appears to have a very stable relationship with correlations.

Thus, this paper provides some implications for investment. First, in recent periods, it is very difficult to find negatively correlated stock indices, which are necessary to construct a sound financial portfolio. It follows that it is not easy to minimize financial losses, as the capital 
asset pricing model suggests, when the market is very weak. Thus, at best, one could gather weakly correlated stocks in a portfolio, although their correlation may be positive. Second, the traditional approach to investment portfolios remains unchanged even today: investors willing to diversify their portfolio should pick stocks from a variety of locations. Third, a relatively low correlation between financial assets in different levels of economic development implies that a sound financial portfolio should contain stocks not only from countries in different geographical locations but also from different income groups.

From the perspective of policymakers, our findings imply that in a highly integrated world it is difficult to keep a home foreign exchange market away from overseas effects, which become stronger at times of active trading and thus during crises. The government and the central bank, however, could encourage dissemination of information in order to reduce information asymmetry, which is argued as triggering investors' herding behaviour and thus may result in extra and unnecessary increases in trade volume.

Received 09 March 2013, Revised 07 May 2013, Accepted 11 June 2013

\section{References}

Al-Rjoub, S. A. M. and H. Azzam (2012), 'Financial crises, stock returns and volatility in an emerging stock market,' Journal of Economic Studies 39, 178-211.

Baele, L., A. Ferrando, P. Hordahl, E. Krylova and C. Monnet (2004) 'Measuring financial integration in the euro area,' European Central Bank Occasion Paper Series No. 14.

Baker, D. and T. Loughran (2007) 'The geography of S\&P500 stock returns,' Journal of Behavioral Finance 8, 177-190.

Bayoumi, T., G. Fazio, M. Kumar and R. MacDonald (2007) 'Fatal attraction: using distance to measure contagion in good times as well as bad,' Review of Financial Economics 16, 259-273.

Bollerslev, T., R. F. Engle and J.M. Wooldridge (1988) 'A capital asset pricing model with time-varying covariances,' Journal of Political Economy 96, 116-131.

Calvo, S. and C.M. Reinhart, C. M. (1996) 'Capital flows to Latin America: is there evidence of contagion effects?’ In Calvo, G. A., Goldstein, M., Hochreiter, E. (Eds.) Private Capital Flows to Emerging Markets After the Mexican Crisis. Washington DC: Institute for International Economics (1996).

Chen, N-F. and F. Zhang, F. (1997) 'Correlations, trades, and stock returns of the Pacific-Basin markets,' Pacific-Basin Finance Journal 5, 559-577.

Chintrakarn, P. and P. Prasatkitjaroen (2010) 'Reassessing the determinants of international stock market correlation,' International Research Journal of Finance and Economics 60, 7-14.

Choi, K. and S. Hammoudeh, 2010, 'Volatility behavior of oil, industrial commodity and stock markets in a regime-switching environment,' Energy Policy 38, 4388-4399.

Easley, D., Kiefer, N. and M. O’Hara (1997) 'The information content of the trading process,' Journal of 
Empirical Finance 4, 159-186.

Engle, R. (2002) 'Dynamic conditional correlation: a simple class of multivariate generalized autoregressive conditional heteroskedasticity models," Journal of Business and Economic Statistics 20, 339-350.

Engle, R. F. and K. Sheppard (2001) 'Theoretical and empirical properties of dynamic conditional correlation multivariate GARCH," Mimeo,UCSD.

Fidrmuc, J., K. Iwatsubo and T. Ikeda (2012) 'International transmission of business cycles: evidence from dynamic correlations,' Economic Letters 114, 252-255.

Flavin, T. J., M.J. Hurley and F. Rousseau (2002) 'Explaining stock market correlation: a gravity model approach,' Manchester School, 87-106.

Greene, M.T. and B.D. Fielitz, B. D. (1977) 'Long-term dependence in common stock returns,' Journal of Financial Economics 4, 339-349.

Hamao, Y., R.W. Masulis and V. Ng (1990) 'Correlations in price changes and volatility across international stock markets,' Review of Financial Studies 3, 281-307.

Kaminsky, G.L. (1993) 'Is there a peso problem? evidence from the Dollar/Pound exchange rate, 1976-1987,' American Economic Review 83, 450-472.

King, M. A. and S. Wadhwani (1990) 'Transmission of volatility between stock markets,' Review of Financial Studies 3, 5-33.

Kuper, G. H. and Lestano (2007) 'Dynamic conditional correlation analysis of financial market interdependence: an application to Thailand and Indonesia,' Journal of Asian Economics 18, 670-684.

Lahrech, A. and K. Sylwester (2011) 'US and Latin American stock market linkages,' Journal of International Money and Finance 30, 1341-1357.

Lettau, M. and S. Ludvigson (2001) 'Consumption, aggregate wealth, and expected stock returns,' Journal of Finance 56, 815-849.

Levy, H. and M. Sarnat (1970) 'International diversification of investment portfolio,' American Economic Review 60, 668-675.

Lin, W-L., R.F. Engle and T. Ito (1994) 'Do bulls and bears move across borders? international transmission of stock returns and volatility,' Review of Financial Studies 7, 507-38.

Liu, Y. A., M-S. Pan and J.C.P. Shieh (1998) 'International transmission of stock price movements: evidence from the US and five Asian-Pacific Markets,' Journal of Economics and Finance 22, 59-69.

Longin, F. and B. Solnik (1995) 'Is the correlation in international equity returns constant: 1960-1990,' Journal of International Money and Finance 14, 3-26.

Nagayasu, J. (2013) 'The forward premium puzzle and the euro,' MPRA Paper 45746, University Library of Munich, Germany.

Makridakis, S. G. and S.C. Wheelwright (1974) 'An analysis of the interrelationships among the major world stock exchanges,' Journal of Business, Finance and Accounting 1, 195-215.

Masih, A. M. and R. Masih (1997) 'Dynamic linkages and the propagation mechanism driving major international stock markets: an analysis of the pre- and post-crash eras,' Quarterly Review of Economics and Finance 37, 859-885. 
Pretorius, E. (2002) 'Economic determinants of emerging stock market interdependence,' Emerging Markets Review 3, 84-105.

Roll, R. (1992) 'Industrial structure and the comparative behavior of international stock market indices,' Journal of Finance 47, 3-41.

Tamakoshi, G., Y. Toyoshima and S. Hamori (2012) 'A dynamic conditional correlation analysis of European stock markets from the perspective of the Greek sovereign debt crisis,' Economics Bulletin 32, 437-448.

Tse, Y. K. (2000) 'A test for constant correlations in a multivariate GARCH Model,' Journal of Econometrics $98,107-127$.

Yang, S-Y. (2005) 'A DCC analysis of international stock market correlations: the role of Japan on the Asian four tigers,' Applied Financial Economics Letters 1, 89-93. 


\section{Appendix. Definitions and Sources of Variables}

Stock prices and returns Stock price (adj close) data are downloaded from at http://finance. yahoo.com, and stock returns $\left(r_{i t}\right)$ are calculated as: $\left(p_{i t}-p_{i t-1}\right)$, where $p$ is a $\log$ price with subscripts $i$ for countries $(i=1, \ldots, 9)$ and $t$ for time.

Dist

$\mathrm{Vol}_{i}, \mathrm{Vol}_{j}$ The distance between the financial centers of countries $(\mathrm{km})$

| CapDiff ${ }_{i j}$ The volume of stocks traded in a day in countries $i$ and $j$. Data are downloaded from at http://finance.yahoo.com. The absolute value of differences in market capitalization between countries $i$ and $j$. The data are downloaded from DataStream.

| IntDiff ${ }_{i j}$ The absolute value of interest rate differentials between countries $i$ and $j$. The three-month market rates for each country are downloaded from DataStream.

ChinaDummy Dummy variable ( $=1$ for the country pairs of China-HK, China-Taiwan and HK-Taiwan, and $=0$ otherwise)

See Table 5 for further information about Dist. See Table 4 for country pairs ( $i$ and $j$ ). Due to the non-availability of volume data for all of our countries from DataStream, both stock price and volume data are downloaded from at http://finance.yahoo.com.

Table 1. List of Stock Indices

\begin{tabular}{ll|ll}
\hline Country (abbreviation) & Stock index & Country & Stock index \\
\hline Australia (AUS) & All Ordinaries & Japan (JAP) & Nikkei225 \\
China (CHI) & Shanghai Composite & New Zealand (NZ) & NZSE50 \\
Hong Kong (HK) & Hang Seng & Korea (KOR) & KOSPI Composite \\
India (IND) & BSE 30 & Taiwan (TAIW) & Taiwan Weighted \\
Indonesia (INDO) & Jakarta Composite & & \\
\hline
\end{tabular}

(Note) Daily data on adjusted stock prices and volumes are downloaded from at http://finance.yahoo.com. 
Table 2. Basic Statistics of Stock Returns

\begin{tabular}{|c|c|c|c|c|c|c|}
\hline Univariate test & Mean & Std. Dev & Min & Max & $\mathrm{ARCH}(5$ lags $)$ & $\mathrm{ARCH}(10$ lags $)$ \\
\hline Australia & $2.0 \mathrm{E}-05$ & 0.054 & -0.086 & 0.054 & $\begin{array}{l}\mathrm{F}(5,1491)= \\
73.361[0.0000]\end{array}$ & $\begin{array}{l}\mathrm{F}(10,1481)= \\
44.156[0.0000]\end{array}$ \\
\hline China & $6.0 \mathrm{E}-04$ & 0.090 & -0.093 & 0.090 & $\begin{array}{l}F(5,1491)= \\
13.989[0.0000]\end{array}$ & $\begin{array}{l}F(10,1481)= \\
10.176[0.0000]\end{array}$ \\
\hline Hong Kong & $2.6 \mathrm{E}-04$ & 0.134 & -0.136 & 0.134 & $\begin{array}{l}\mathrm{F}(5,1491)= \\
96.533[0.0000]\end{array}$ & $\begin{array}{l}F(10,1481)= \\
57.028[0.0000]\end{array}$ \\
\hline India & $5.2 \mathrm{E}-04$ & 0.160 & -0.116 & 0.160 & $\begin{array}{l}\mathrm{F}(5,1491)= \\
21.342[0.0000]\end{array}$ & $\begin{array}{l}F(10,1481)= \\
16.389[0.0000]\end{array}$ \\
\hline Indonesia & $8.6 \mathrm{E}-04$ & 0.076 & -0.110 & 0.076 & $\begin{array}{l}F(5,1491)= \\
42.161[0.0000]\end{array}$ & $\begin{array}{l}\mathrm{F}(10,1481)= \\
21.699[0.0000]\end{array}$ \\
\hline Japan & $-2.0 \mathrm{E}-04$ & 0.132 & -0.121 & 0.132 & $\begin{array}{l}F(5,1491)= \\
151.08[0.0000]\end{array}$ & $\begin{array}{l}F(10,1481)= \\
80.894[0.0000]\end{array}$ \\
\hline Korea & $3.6 \mathrm{E}-04$ & 0.113 & -0.112 & 0.113 & $\begin{array}{l}\mathrm{F}(5,1491)= \\
94.499[0.0000]\end{array}$ & $\begin{array}{l}\mathrm{F}(10,1481)= \\
56.938[0.0000]\end{array}$ \\
\hline $\mathrm{NZ}$ & $9.2 \mathrm{E}-07$ & 0.058 & -0.049 & 0.058 & $\begin{array}{l}F(5,1491)= \\
150.35[0.0000]\end{array}$ & $\begin{array}{l}\mathrm{F}(10,1481)= \\
84.583[0.0000]\end{array}$ \\
\hline Taiwan & $2.2 \mathrm{E}-04$ & 0.065 & -0.067 & 0.065 & $\begin{array}{l}\mathrm{F}(5,1491)= \\
35.227[0.0000]\end{array}$ & $\begin{array}{l}\mathrm{F}(10,1481)= \\
20.035[0.0000]\end{array}$ \\
\hline
\end{tabular}

Constant

Correlation tests

LM Test for Constant Correlation of Tse (2000)

$$
185.086 \quad[0.000]
$$

Engle-Sheppard Test (2001) for Dynamic Correlation

$$
20.144 \quad[0.003]
$$

(Note) The number in parentheses for statistical tests corresponds to the degrees of freedom. The number in brackets is a $p$-value. 
Table 3. AR(1)-DCC-GARCH Results for Stock Returns

\begin{tabular}{|c|c|c|c|c|}
\hline 1st-stage & Coef & SE & $T$-value & $P$-value \\
\hline \multicolumn{5}{|c|}{ Australia } \\
\hline Constant(M) & 0.001 & 0.000 & 2.827 & 0.005 \\
\hline $\operatorname{AR}(1)$ & -0.070 & 0.026 & -2.718 & 0.007 \\
\hline Constant (V) $\times 10^{\wedge} 4$ & 0.023 & 0.010 & 2.433 & 0.015 \\
\hline $\mathrm{ARCH}$ & 0.114 & 0.026 & 4.473 & 0.000 \\
\hline GARCH & 0.872 & 0.026 & 33.700 & 0.000 \\
\hline $\mathrm{Q}(5)^{\mathrm{a}}$ & & & 8.125 & 0.150 \\
\hline $\mathrm{Q}(5)^{\mathrm{b}}$ & & & 3.062 & 0.690 \\
\hline \multicolumn{5}{|c|}{ China } \\
\hline Constant (M) & 0.001 & 0.000 & 2.154 & 0.031 \\
\hline $\mathrm{AR}(1)$ & -0.006 & 0.028 & -0.230 & 0.818 \\
\hline Constant $(\mathrm{V}) \times 10^{\wedge} 4$ & 0.026 & 0.015 & 1.818 & 0.069 \\
\hline $\mathrm{ARCH}$ & 0.061 & 0.012 & 4.968 & 0.000 \\
\hline GARCH & 0.933 & 0.014 & 68.280 & 0.000 \\
\hline $\mathrm{Q}(5)^{\mathrm{a}}$ & & & 11.423 & 0.044 \\
\hline $\mathrm{Q}(5)^{\mathrm{b}}$ & & & 3.666 & 0.598 \\
\hline \multicolumn{5}{|c|}{ Hong Kong } \\
\hline Constant (M) & 0.001 & 0.000 & 2.353 & 0.019 \\
\hline $\operatorname{AR}(1)$ & -0.003 & 0.026 & -0.114 & 0.909 \\
\hline Constant (V) $\times 10^{\wedge} 4$ & 0.022 & 0.010 & 2.312 & 0.021 \\
\hline $\mathrm{ARCH}$ & 0.091 & 0.015 & 6.109 & 0.000 \\
\hline GARCH & 0.902 & 0.015 & 59.100 & 0.000 \\
\hline $\mathrm{Q}(5)^{\mathrm{a}}$ & & & 5.674 & 0.339 \\
\hline$Q(5)^{b}$ & & & 5.276 & 0.383 \\
\hline \multicolumn{5}{|c|}{ India } \\
\hline Constant (M) & 0.001 & 0.000 & 3.462 & 0.001 \\
\hline $\operatorname{AR}(1)$ & 0.060 & 0.030 & 1.965 & 0.050 \\
\hline Constant (V) $\times 10^{\wedge} 4$ & 0.047 & 0.018 & 2.538 & 0.011 \\
\hline $\mathrm{ARCH}$ & 0.123 & 0.027 & 4.572 & 0.000 \\
\hline GARCH & 0.868 & 0.025 & 34.890 & 0.000 \\
\hline $\mathrm{Q}(5)^{\mathrm{a}}$ & & & 9.955 & 0.077 \\
\hline $\mathrm{Q}(5)^{\mathrm{b}}$ & & & 4.517 & 0.478 \\
\hline \multicolumn{5}{|c|}{ Indonesia } \\
\hline Constant (M) & 0.001 & 0.000 & 4.460 & 0.000 \\
\hline $\operatorname{AR}(1)$ & 0.078 & 0.032 & 2.466 & 0.014 \\
\hline Constant (V) $\times 10^{\wedge} 4$ & 0.061 & 0.034 & 1.810 & 0.071 \\
\hline $\mathrm{ARCH}$ & 0.104 & 0.024 & 4.324 & 0.000 \\
\hline GARCH & 0.872 & 0.037 & 23.480 & 0.000 \\
\hline $\mathrm{Q}(5)^{\mathrm{a}}$ & & & 4.929 & 0.425 \\
\hline $\mathrm{Q}(5)^{\mathrm{b}}$ & & & 2.671 & 0.751 \\
\hline
\end{tabular}


Constant (M)

$\operatorname{AR}(1)$

Constant (V) x10^4

$\mathrm{ARCH}$

GARCH

$\mathrm{Q}(5)^{\mathrm{a}}$

$\mathrm{Q}(5)^{\mathrm{b}}$

Constant (M)

$\operatorname{AR}(1)$

Constant (V) $\times 10^{\wedge} 4$

$\mathrm{ARCH}$

GARCH

$\mathrm{Q}(5)^{\mathrm{a}}$

$\mathrm{Q}(5)^{\mathrm{b}}$

Constant (M)

AR(1)

Constant (V) $\times 10^{\wedge} 6$

$\mathrm{ARCH}$

GARCH

$\mathrm{Q}(5)^{\mathrm{a}}$

$\mathrm{Q}(5)^{\mathrm{b}}$

Constant (M)

AR(1)

Constant (V) $\times 10^{\wedge} 4$

$\mathrm{ARCH}$

GARCH

$\mathrm{Q}(5)^{\mathrm{a}}$

$\mathrm{Q}(5)^{\mathrm{b}}$

Japan

$\begin{array}{rrrr}0.000 & 0.000 & 1.330 & 0.184 \\ -0.035 & 0.025 & -1.381 & 0.167 \\ 0.060 & 0.021 & 2.878 & 0.004 \\ 0.128 & 0.025 & 5.121 & 0.000 \\ 0.852 & 0.025 & 34.690 & 0.000 \\ & & 1.052 & 0.958 \\ & & 11.083 & 0.050\end{array}$

Korea

$\begin{array}{rrrr}0.001 & 0.000 & 3.063 & 0.002 \\ -0.007 & 0.026 & -0.271 & 0.787 \\ 0.027 & 0.010 & 2.552 & 0.011 \\ 0.080 & 0.016 & 5.079 & 0.000 \\ 0.907 & 0.017 & 52.670 & 0.000 \\ & & 2.416 & 0.789 \\ & & 7.208 & 0.206\end{array}$

New Zealand

0.000

0.000

2.087

0.037

0.049

0.028

1.763

0.078

0.947

0.576

1.644

0.100

0.078

0.023

3.420

0.001

0.904

0.032

28.510

0.000

11.580

0.041

6.303

0.278

Taiwan

2nd-step

\begin{tabular}{lrrrr}
\hline ARCH & 0.015 & 0.003 & 4.627 & 0.000 \\
GARCH & 0.910 & 0.028 & 31.960 & 0.000 \\
\hline
\end{tabular}

(Note) a: Q-statistics on standardized residuals, b: Q-statistics on squared standardized residuals. The numbers in parentheses for $\mathrm{Q}$ tests are degrees of freedom. $\mathrm{M}$ and $\mathrm{V}$ in parentheses represent the mean and conditional variance equations. 
Table 4. Basic Statistics of Conditional Correlations

\begin{tabular}{|c|c|c|c|c|c|}
\hline \multicolumn{2}{|l|}{ Full sample } & \multicolumn{2}{|l|}{ Crisis I } & \multicolumn{2}{|l|}{ Crisis II } \\
\hline Country pair $\left(i \_j\right)$ & Mean & Country pair $\left(i \_j\right)$ & Mean & Country pair $\left(i \_j\right)$ & Mean \\
\hline AUS_JAP & 0.653 & JAP_KOR & 0.665 & JAP_KOR & 0.662 \\
\hline JAP_KOR & 0.652 & AUS_JAP & 0.656 & KOR_TAIW & 0.655 \\
\hline KOR_TAIW & 0.642 & KOR_TAIW & 0.653 & AUS_JAP & 0.649 \\
\hline AUS_HK & 0.639 & HK_KOR & 0.639 & AUS_HK & 0.638 \\
\hline HK_KOKOR & 0.633 & AUS_HK & 0.639 & HK_K_KOR & 0.632 \\
\hline AUS_KOR & 0.609 & AUS_KOR & 0.613 & AUS_KOR & 0.611 \\
\hline HK_JAP & 0.587 & HK_JAP & 0.593 & HK_TAIW & 0.589 \\
\hline HK_INDO & 0.578 & HK_TAIW & 0.578 & HK_JAP & 0.586 \\
\hline HK_TAIW & 0.576 & HK_INDO & 0.575 & HK_INDO & 0.572 \\
\hline JAP_TAIW & 0.556 & JAP_TAIW & 0.565 & JAP_TAIW & 0.571 \\
\hline AUS_TAIW & 0.554 & AUS_TAIW & 0.558 & AUS_TAIW & 0.570 \\
\hline AUS_NZ & 0.520 & AUS_NZ & 0.535 & AUS_NZ & 0.511 \\
\hline HK_IND & 0.516 & HK_IND & 0.529 & HK_IND & 0.506 \\
\hline INDO_KOR & 0.476 & AUS_INDO & 0.474 & INDO_KOROR & 0.484 \\
\hline AUS_INDO & 0.475 & INDO_KOR & 0.472 & AUS_INDO & 0.474 \\
\hline IND_INDO & 0.446 & CHI_HK & 0.453 & CHI_HK & 0.452 \\
\hline INDO_JAP & 0.442 & IND_INDO & 0.445 & INDO_JAP & 0.450 \\
\hline INDO_TAIW & 0.437 & INDO_JAP & 0.440 & IND_INDO & 0.446 \\
\hline CHI_HK & 0.431 & INDO_TAIW & 0.437 & INDO_TAIW & 0.441 \\
\hline IND_KOR & 0.410 & JAP_NZ & 0.418 & AUS_IND & 0.414 \\
\hline AUS_IND & 0.404 & IND_KOR & 0.411 & JAP_NZ & 0.401 \\
\hline JAP_NZ & 0.404 & AUS_IND & 0.409 & IND_KOR & 0.398 \\
\hline IND_TAIW & 0.354 & IND_TAIW & 0.353 & IND_TAIW & 0.355 \\
\hline HK_NZ & 0.337 & NZ_KOR & 0.353 & NZ_KOR & 0.331 \\
\hline IND_JAP & 0.337 & HK_NZ & 0.348 & IND_JAP & 0.323 \\
\hline NZ_KOR & 0.337 & IND_JAP & 0.344 & CHI_TAIW & 0.319 \\
\hline NZ_TAIW & 0.305 & CHI_KOR & 0.317 & HK_NZ & 0.314 \\
\hline CHI_KOR & 0.296 & NZ_TAIW & 0.313 & CHI_KOR & 0.313 \\
\hline INDO_NZ & 0.291 & CHI_TAIW & 0.299 & NZ_TAIW & 0.303 \\
\hline CHI_TAIW & 0.286 & INDO_NZ & 0.291 & INDO_NZ & 0.284 \\
\hline AUS_CHI & 0.269 & AUS_CHI & 0.281 & CHI_JAP & 0.279 \\
\hline CHI_JAP & 0.264 & CHI_JAP & 0.274 & AUS_CHI & 0.274 \\
\hline CHI_INDO & 0.249 & CHI_INDO & 0.265 & CHI_INDO & 0.260 \\
\hline IND_NZ & 0.229 & CHI_IND & 0.244 & IND_NZ & 0.235 \\
\hline CHI_IND & 0.228 & IND_NZ & 0.241 & CHI_IND & 0.233 \\
\hline CHI_NZ & 0.189 & CHI_NZ & 0.198 & CHI_NZ & 0.170 \\
\hline Average & 0.434 & Average & 0.441 & Average & 0.436 \\
\hline
\end{tabular}

(Note) The average of conditional correlations obtained from the AR-DCC-GARCH. Crisis I (2008/01/012009/06/12) and Crisis II (2009/12/08 2010/05/02). Countries listed on the left and right in a country pair are denoted as $i$ and $j$ respectively in equation (5). For example, AUS_JAP are a country pair for $i$ (Australia) and $j$ (Japan). 
Table 5. Geographical Distance between Financial Markets

$(\mathrm{km})$

\begin{tabular}{l|ccccccccc}
\hline & AUS & CHI & HK & IND & INDO & JAP & NZ & KOR & TAIW \\
\hline AUS & 0 & & & & & & & & \\
CHI & 7889 & 0 & & & & & & & \\
HK & 7394 & 1225 & 0 & & & & & & \\
IND & 10440 & 4250 & 3755 & 0 & & & & & \\
INDO & 5502 & 4449 & 3282 & 5013 & 0 & & & & \\
JAP & 7834 & 1760 & 2886 & 5847 & 5793 & 0 & & & \\
NZ & 2228 & 9727 & 9433 & 12569 & 7726 & 9248 & 0 & & \\
KOR & 8338 & 867 & 2091 & 4690 & 5303 & 1160 & 10003 & 0 & \\
TAIW & 7273 & 684 & 816 & 4396 & 3832 & 2100 & 9180 & 1481 & 0 \\
\hline
\end{tabular}

(Note) Full sample. Australia(AUS), China(CHI), India(IND), Indonesia(INDO), Japan(JAP), Korea(KOR), and Taiwan(TAIW).

Table 6. Determinants of Conditional Correlations

\begin{tabular}{lcccccc}
\hline & & {$[\mathrm{A}]$} & & & {$[\mathrm{B}]$} & \\
& Coef & SE & $P$-value & Coef & SE & $P$-value \\
\hline Vol $_{i}(\mathrm{t}-1)$ & 0.003 & 0.000 & 0.000 & 0.003 & 0.000 & 0.000 \\
Vol $_{j}(\mathrm{t}-1)$ & 0.002 & 0.000 & 0.000 & 0.002 & 0.000 & 0.000 \\
$\mid$ CapDiff $(\mathrm{t}-1) \mid$ & -0.003 & 0.000 & 0.000 & -0.003 & 0.000 & 0.000 \\
Dist & -0.072 & 0.035 & 0.039 & -0.044 & 0.029 & 0.134 \\
$\mid$ IntDiff(t-1) $\mid$ & -0.001 & 0.000 & 0.000 & -0.001 & 0.000 & 0.000 \\
ChinaDummy & -0.141 & 0.101 & 0.162 & & & \\
Constant & 0.984 & 0.295 & 0.001 & 0.739 & 0.243 & 0.002 \\
Sigma_u & 0.136 & 0.016 & & 0.140 & 0.016 & \\
Sigma_e & 0.036 & 0.000 & & 0.036 & 0.000 & \\
rho & 0.936 & 0.014 & & 0.939 & 0.013 & \\
\hline
\end{tabular}

(Note) Based on equation (5). The abbreviations of variables are explained in Section $\mathrm{V}$ and the Appendix. $\mathrm{u}$ represents the unobservable individual specific effect which is assumed to be random, and e is the rest of the residual. rho is the fraction of variance due to $\mathrm{u}$. The total number of observations is 53,756. Dist is measured in $1,000 \mathrm{~km}$. 
Figure 1. Stock Prices
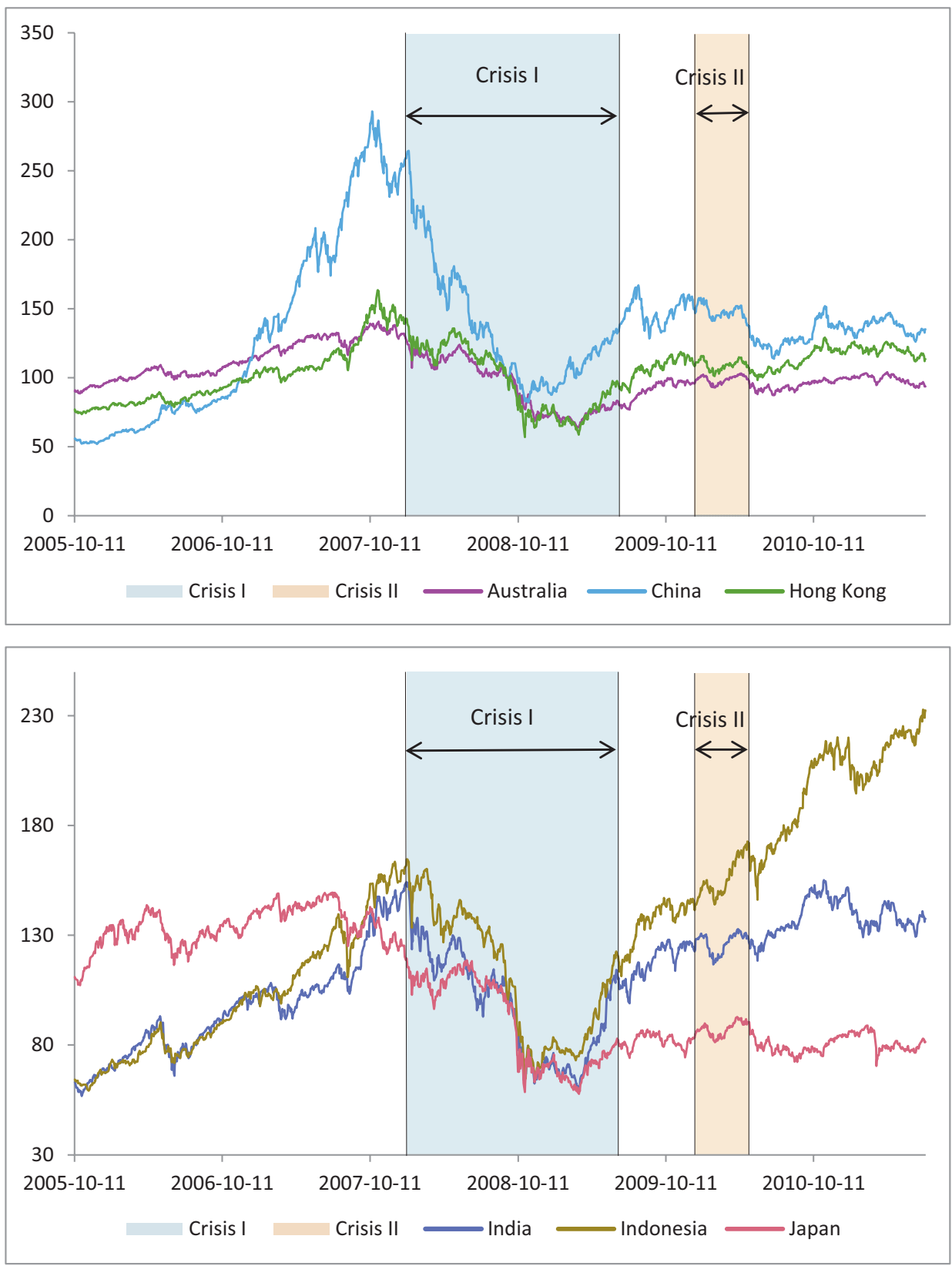
Figure 1. Continued.

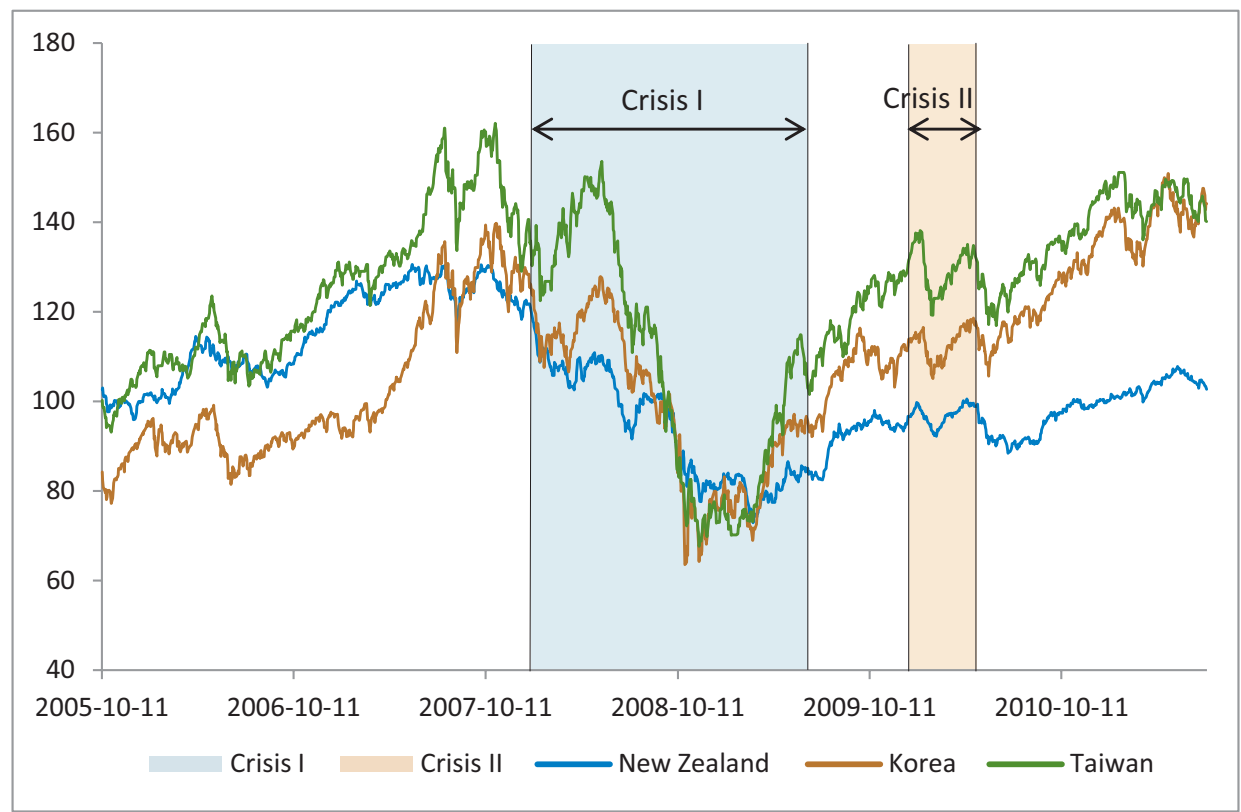

(Note) Stock prices are originally expressed in the local currency and are equal to 100 on 15 September 2008. Crisis I (2008/01/01 2009/06/12) and Crisis II (2009/12/08 2010/05/02). 
Figure 2. Conditional Correlation
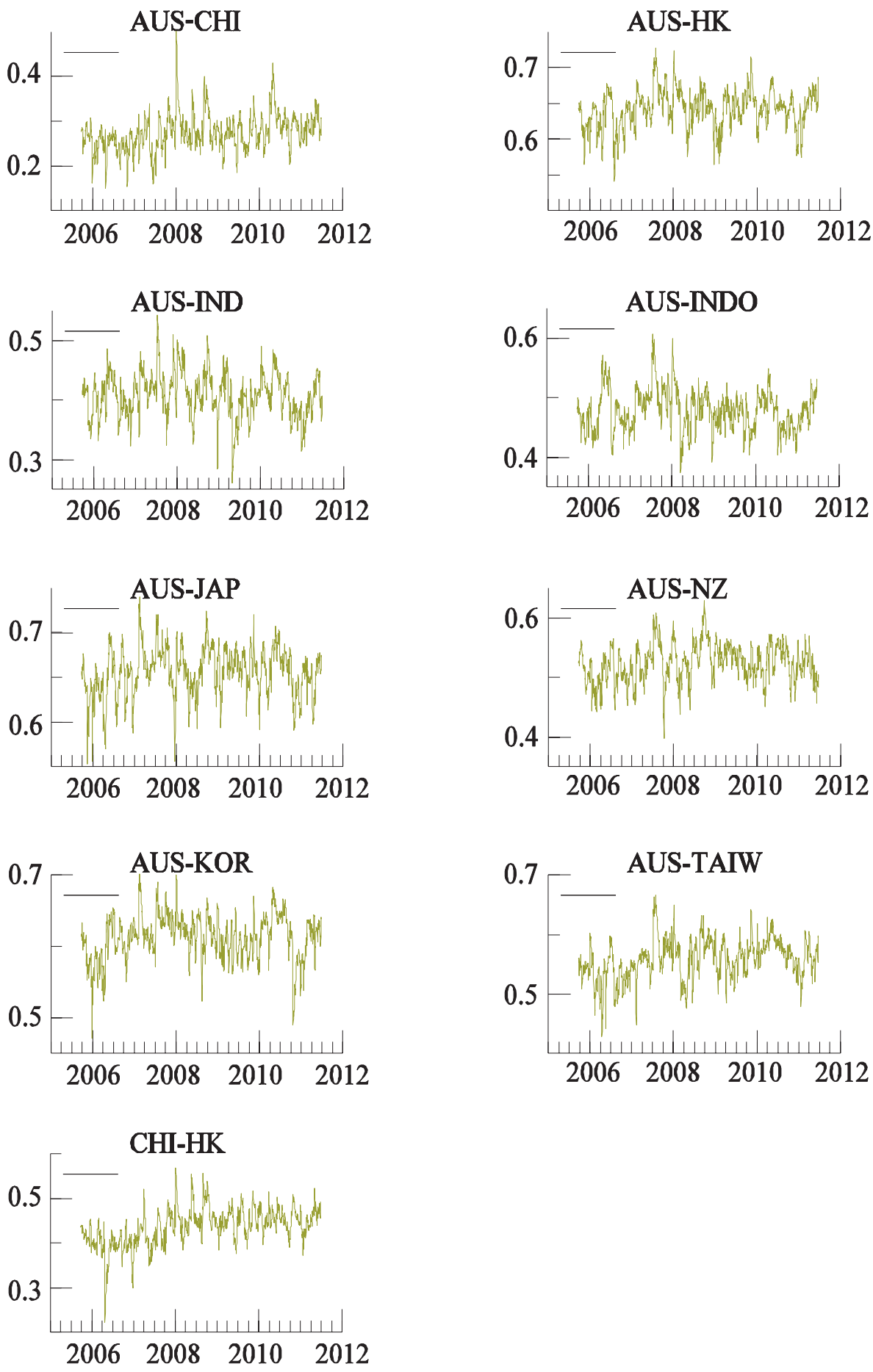

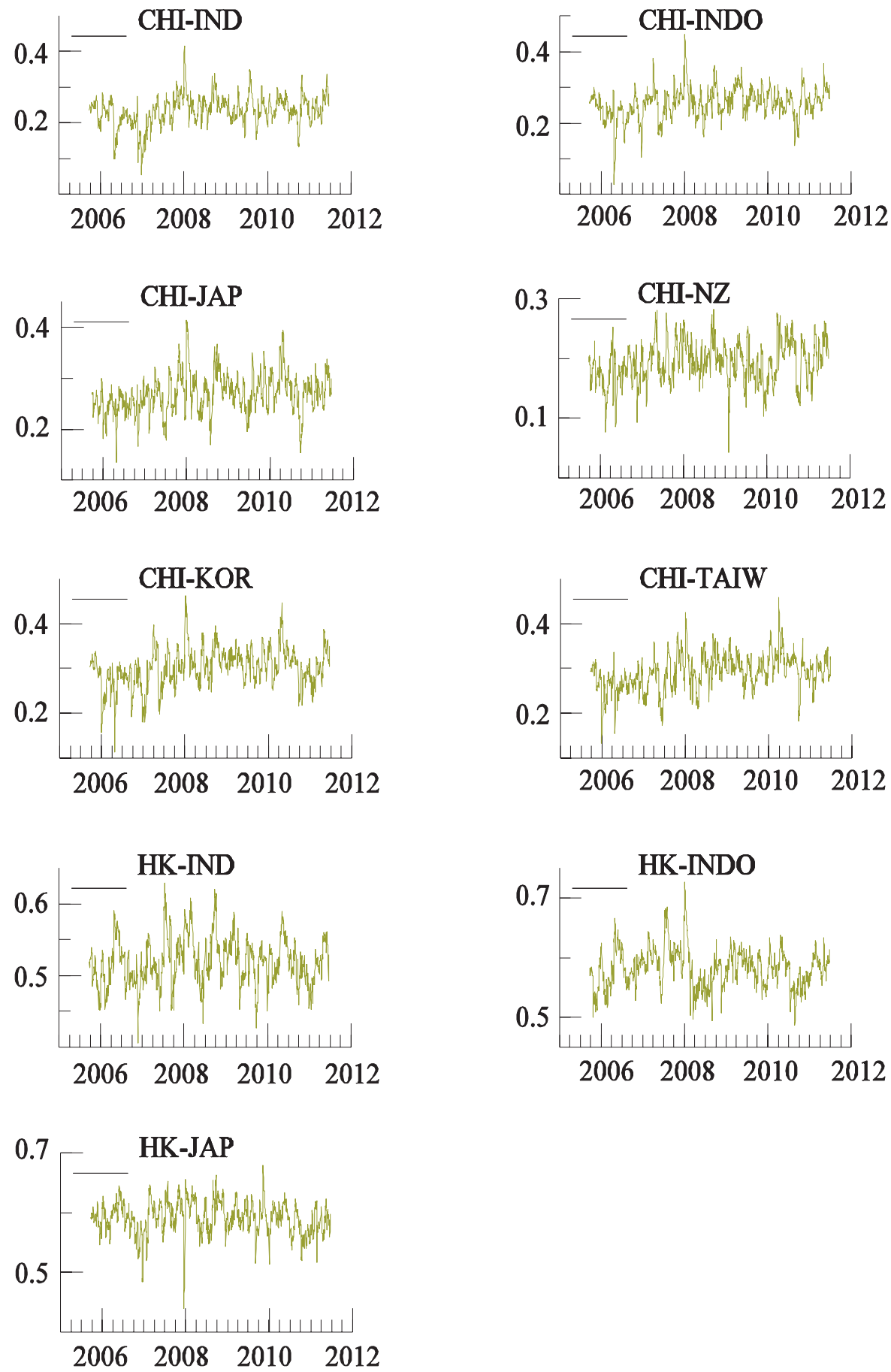

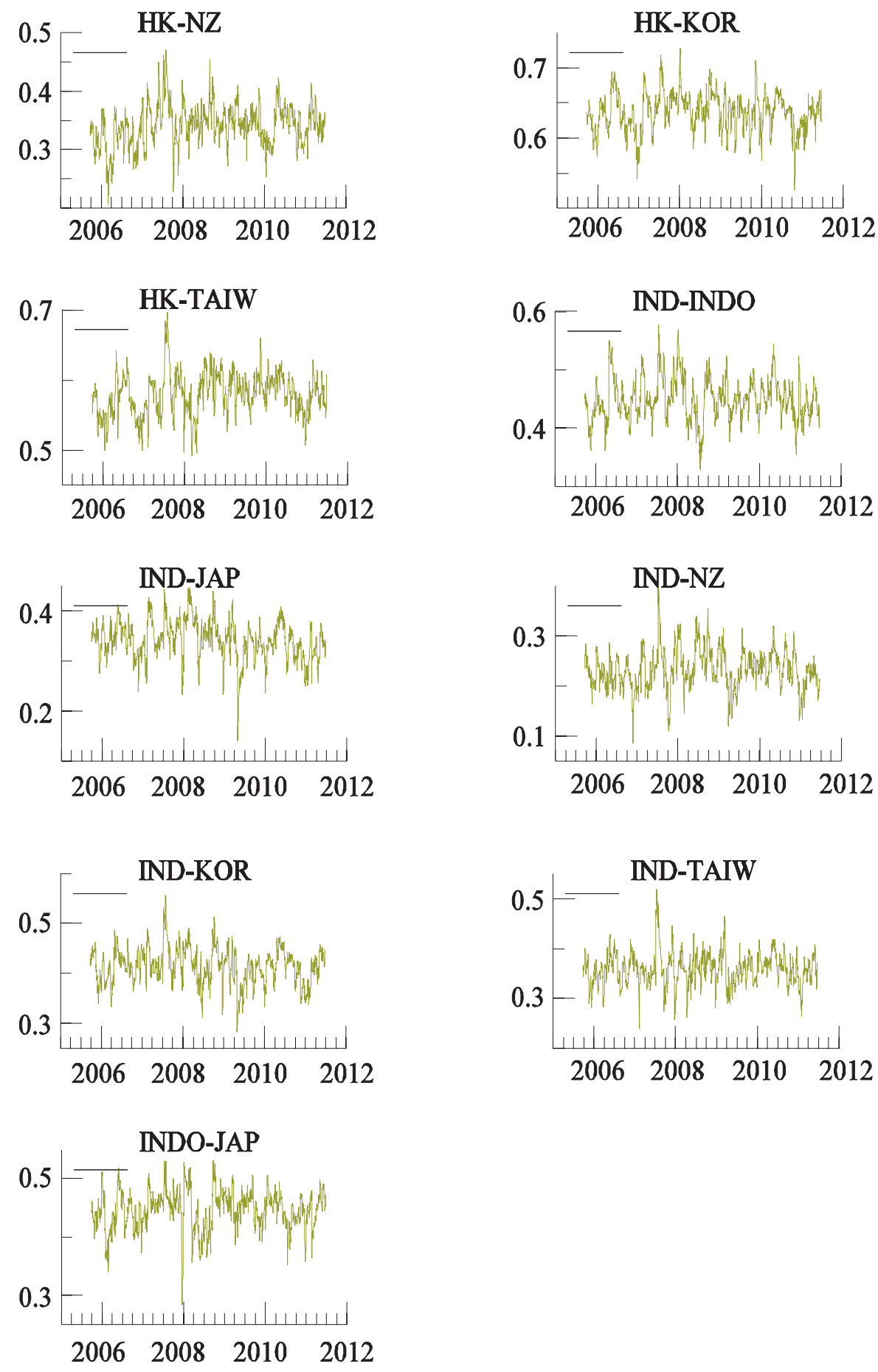

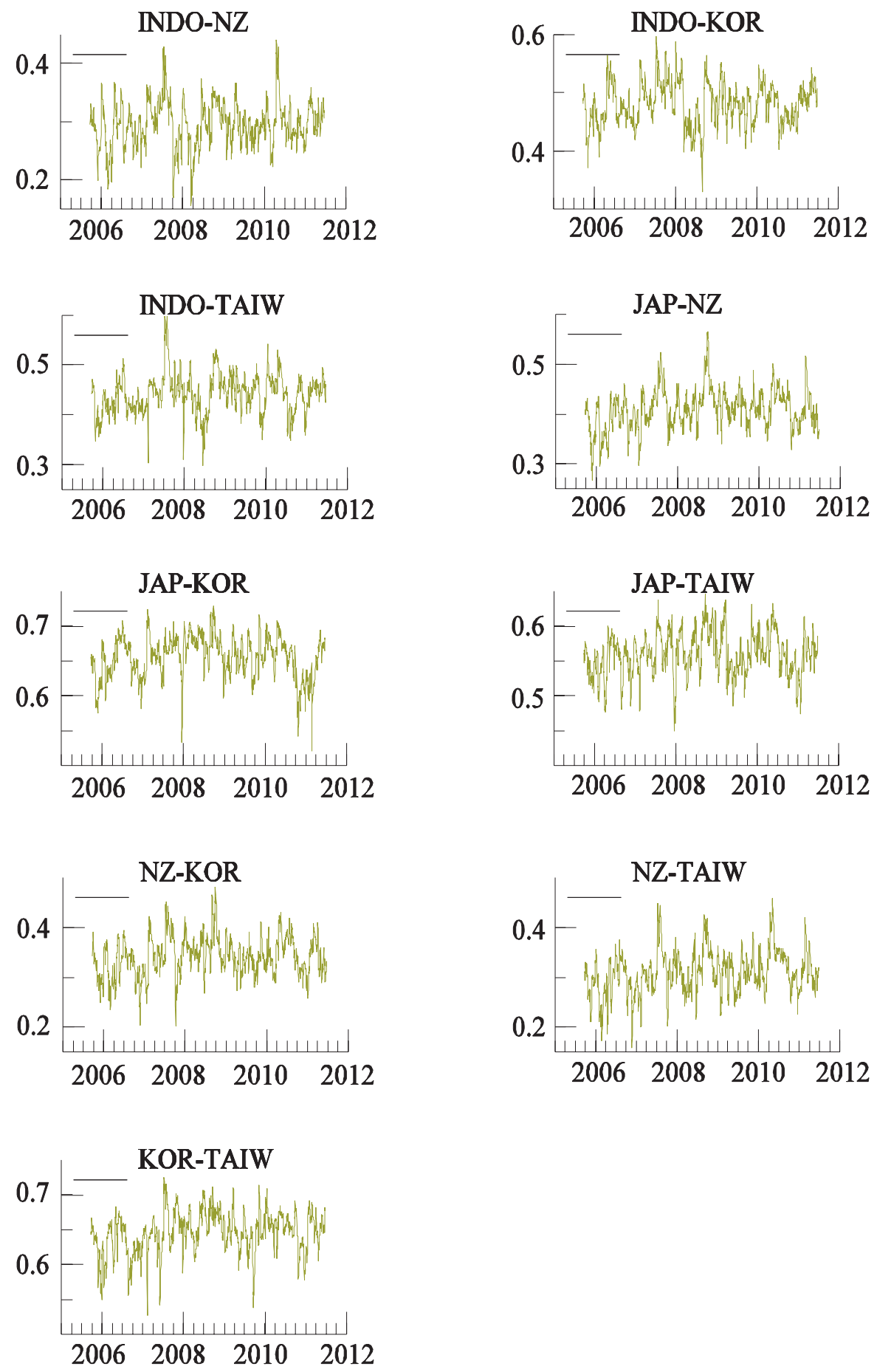
Figure 3. Parameter Stability with $95 \%$ Critical Bands

[A] Volume $i\left(\mathrm{Vol}_{i}\right)$

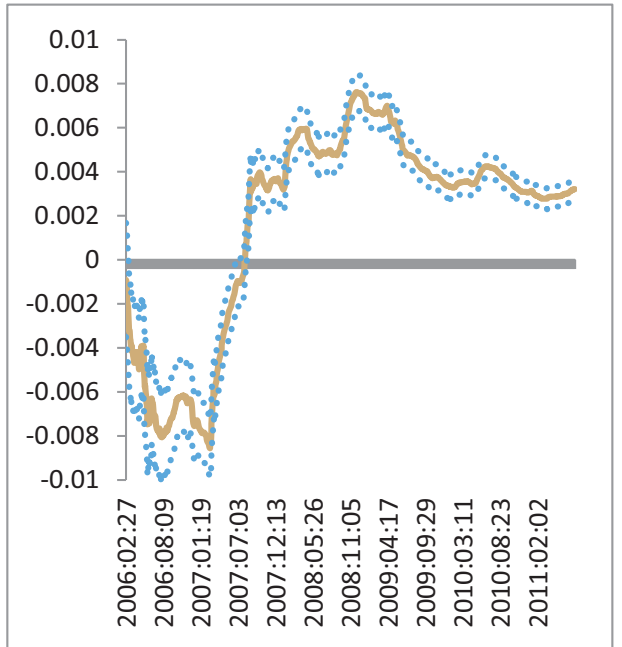

[C] Market Size (|CapDiff $\mid)$

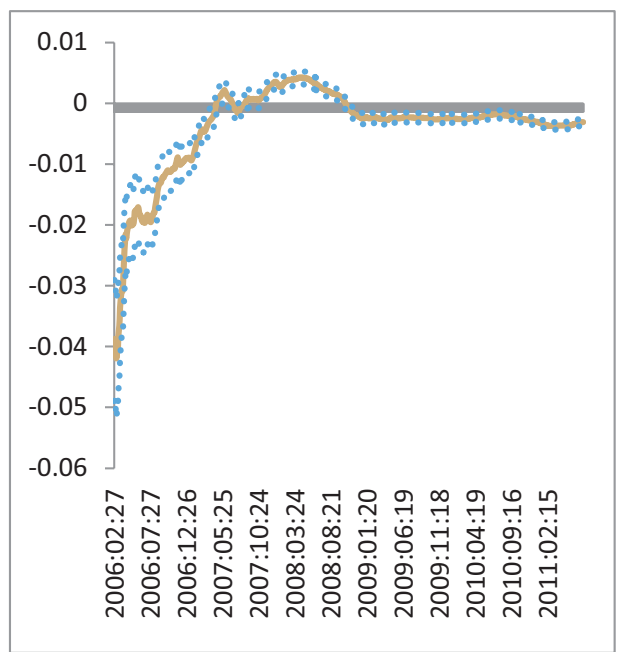

[B] Volume_j $\left(\mathrm{Vol}_{j}\right)$

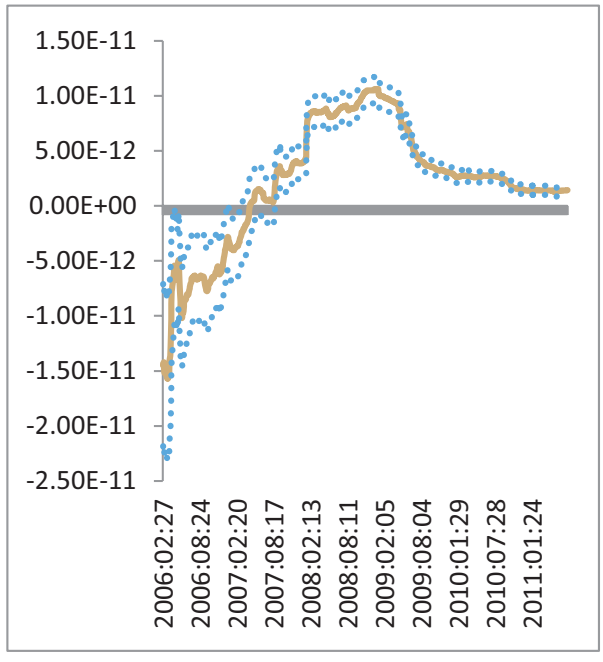

[D] Interest Differentials (|IntDiff $\mid)$

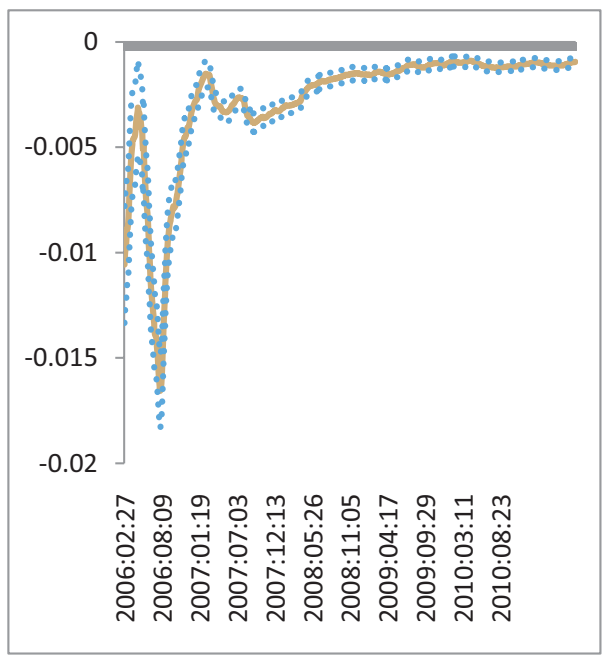


[E] Distance (Dist)

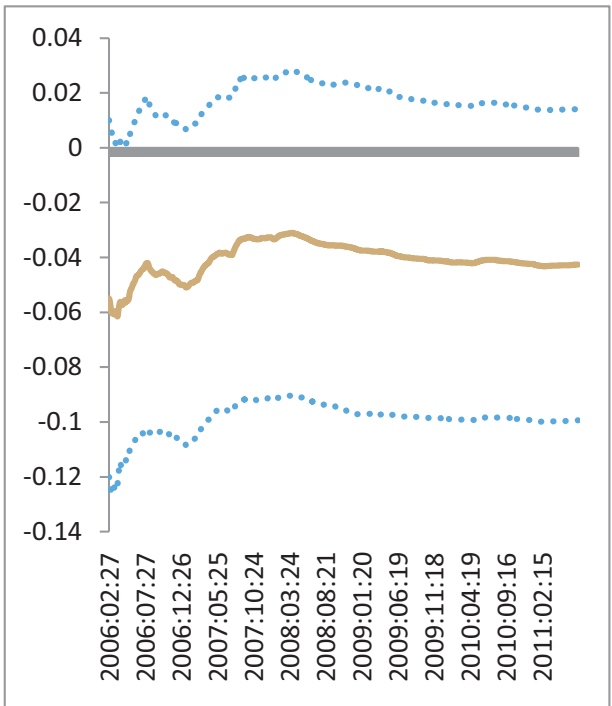

[F] Constant

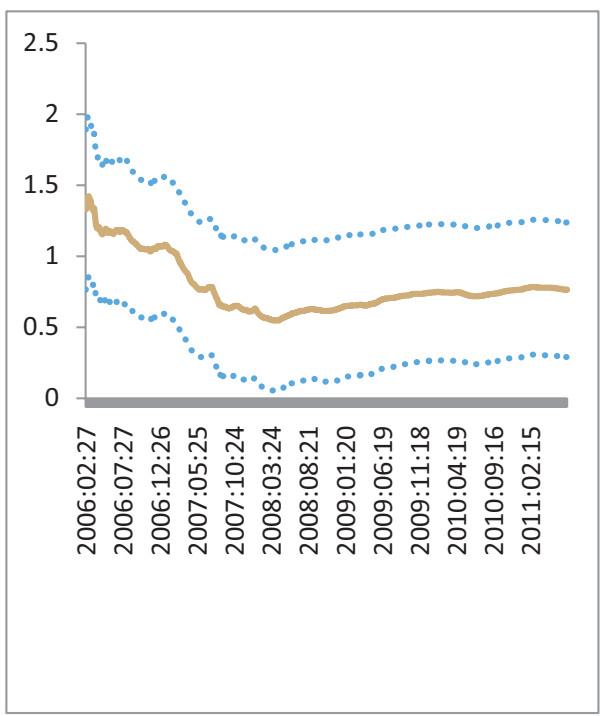

(Note) Estimates with a 5\% confidence level. Parameters are estimated recursively based on equation (5). The dates on the $X$ axis indicate the beginning of sample periods for the recursive estimation. 